\title{
Green Shooting: Media Sustainability, A New Trend
}

\author{
Marta Lopera-Mármol 1,*(D) and Manel Jiménez-Morales ${ }^{2}$ (D) \\ 1 CAS Research Group, Pompeu Fabra University, 08002 Barcelona, Spain \\ 2 CINEMA Research Group, Pompeu Fabra University, 08002 Barcelona, Spain; manel.jimenez@upf.edu \\ * Correspondence: marta.lopera@upf.edu
}

check for

updates

Citation: Lopera-Mármol, M.; Jiménez-Morales, M. Green Shooting: Media Sustainability, A New Trend. Sustainability 2021, 13, 3001. https:// doi.org/10.3390/su13063001

Academic Editor: Roberto Caranta

Received: 31 January 2021

Accepted: 4 March 2021

Published: 10 March 2021

Publisher's Note: MDPI stays neutral with regard to jurisdictional claims in published maps and institutional affiliations.

Copyright: (c) 2021 by the authors. Licensee MDPI, Basel, Switzerland. This article is an open access article distributed under the terms and conditions of the Creative Commons Attribution (CC BY) license (https:// creativecommons.org/licenses/by/ $4.0 /)$.

\begin{abstract}
Research on media sustainability has a long tradition of criticising climate change and environmental issues, mainly through content, and while it is important to do so, it seems that the sector is oblivious to the impact that it itself generates. Moreover, sustainability is often (and wrongly) only related to environmental impact, and very little research exists on how the audio-visual sector can be sustainable not only from an environmental standpoint, but also from a socio-cultural and economic one. This article constitutes a relatively new area that has emerged from the notion of Green Shooting, a term used to describe all the practices ranging from the pre-production, production and post-production to the publicising of an audio-visual product: Documentary, television series (including those of streaming platforms), videogame, film, festival or an advertisement. There has been little previous evidence of an academic article that brings together all the practices that several companies and initiatives worldwide have already implemented as emerging solutions to mitigate their impact, including new roles such as eco-assistant. The authors aim to develop an overarching theoretical framework of what already exists in the practical field, and make it available to the academic community.
\end{abstract}

Keywords: sustainability; media; cinema; television; environment; green shooting

\section{Introduction}

In recent years, sustainability indexes have found their place in academic research and many industries, such as textiles, automobile, beauty, among many others. For some time, these sectors have felt the pressure from governments, academics and customer demand to modify their actions towards sustainable practices. Thus, it seems that in the 21st century, sustainability will define businesses and require consumers' consciousness to embrace these new practices. This article understands the term as defined by the World Business Council for Sustainable Development, which affirmed that sustainability is based on three pillars: Economic growth, ecological balance and social progress aligned with the seventeen Sustainable Development Goals (SDGs) put forward by UNESCO. The interrelationship and balance between these three spheres should be the starting point for action by governments, businesses and other supranational and micro-organizations. Nevertheless, the pillars and SDGs seem to have forgotten one main goal: Culture and its industry. Paradoxically, the media field, with its increasing dependence on viewing via devices, streaming platforms, and audio-visual repositories such as Netflix, Hulu, Filmin, HBO, and Disney + in television and cinema, and characterised by its grand façade of glamor, which usually tends toward excess [1] is one of the most polluting, carbon footprint-producing and socially unequal sectors [2-4]. A 2006 report from UCLA [5] reported that the audio-visual field emits the equivalent of about 1 million tons $\mathrm{CO}_{2}$ into the atmosphere each year. Research on media sustainability has a long tradition of criticizing climate change and environmental issues, mainly through content [2] and while it is important to do so, it seems that the sector is oblivious to the impact that it itself generates. In terms of research, certain eclectic media ecology approaches have been taken, in various domains including those of moral crisis, technological dynamisms and planetary 
materialisms [6]. Hence, the audio-visual field fails to meet many sustainability indexes and lacks knowledge of what the sector itself generates. Many unsustainable practices are going unnoticed, from the misuse of natural resources (non-recyclable systems, overuse of energy on sets, overproduction of clothes and decorations, to mention but a few), enduring racism (like patanking, a type of common, broad, ultra-exaggerated South Asian accent that attempts to enfold thousands of languages and dialects into one single accent [7], whitewashing, and blackface), to ostensibly sexist behavior (the Me-Too movement) [8]. It is important to note that recent academic research focuses on power inequalities across class, gender, and race boundaries, [2] "but there is little if any sustained critical engagement with the more universal phenomenon of ecology" (p. 221).

As Starosielski [4] pointed out, "media distribution emerges as part of an ongoing spatial and environmental history" (p. 41). Thus, it comes as no surprise that Fitzpatrick [9] revealed that during filming in Queensland (Australia) of Pirates of the Caribbean: Dead Men Tell No Tales (Rønning and Sandberg, 2017), chemical waste was allegedly dumped, potentially tainting local water, or that during the filming of Mad Max: Fury Road (Miller, 2015), sensitive environments on the African Atlantic coast were damaged, thus endangering reptiles and cacti. These are not recent phenomena. Furthermore, in 2018, the journal TIME [10] published a worrying article about the negative environmental and cultural impact that the movie The Beach (2000) by Danny Boyle had in the Maya Bay on Ko Phi Phi (Thailand). TIME highlighted how Boyle's production acted to the detriment of cultural tourism by reifying it and, consequently, participating in the loss of its authenticity and identity. For example, as Brereton [2] pointed out "some indigenous directors remain intently aware of Africa's ecology and position themselves differently from Western directors" (p. 220). Thus, it produces an ecological reading from a Western standpoint. This contrasts with ecotourism [11], which is a form of responsible tourism that involves visiting undisturbed natural areas with the intent of minimizing the impacts that other tourism (such as commercial mass tourism) have on the environment and instead resulting in a "positive effect on the host nation's natural and cultural environment" (p. 1). However, films or television can also contribute positively by valuing the local cultural heritage. Thus, it is the responsibility of academics, media experts and professionals to evaluate and guarantee long-term sustainability when producing media actions. There is a political, social, environmental, cultural, and economic danger that should compel and constrain the media routine [9]. It is important to note that many films are labelled as carbon-neutral [12], which means that the carbon dioxide generated by its production was offset by funding environmental groups and planting trees (p. 29). Sometimes do not alter their practices to become environmentally friendly [12] but "merely budgeted an institutional atonement for its pollution" (p. 29). Hence, it is not an eco-friendly movement or production but just a marketable commercial strategy.

However, by focusing research on the range of projects taken on by movements and activist groups, academics, media experts and professionals can find solutions that can improve their practices, from educational proposals to investment in new roles such as eco-assistants, consultants and supervisors, who act as the production's go-to on-set sustainability representatives. They make up the team that is responsible for both monitoring and reducing the show's carbon footprint. "They have a physical presence to educate crew and assist with the everyday practicalities of running an eco-friendly set" [13]. Fortunately, several individual companies and initiatives in practical terms (rather than just academia) are already freely available worldwide that have been created to change certain unsustainable activities of the audio-visual industry, and these have already accomplished remarkable results in making their media contents and their product more sustainable. In this article, we place particular emphasis on the North-American and European perspective. For example, providing toolkits and handbooks on greener practices to producers, helping with carbon calculators, striving for a more diverse cast and many other measures that are discussed further on in this article. For instance, Interreg Europe (a project funded by the European Union), BAFTA Albert (environmental media organization in the United 
Kingdom), Earth Angel NYC (full-service green production based in the USA), BC Creative (full-service green production based in Canada), Fresco Films (production services based in Spain and Portugal that apply sustainable media actions), among many others, and government programs such as the European Green Deal, which is a set of policy initiatives established by the European Commission with the overarching aim of making Europe climate neutral in 2050. Its action plan opts for decarbonizing the energy used, investing in environmentally-friendly technologies, helping the industry to innovate, rolling out cleaner, cheaper, and healthier public and private transport systems, ensuring that buildings are more energy-efficient and collaborating with international partners to improve global environmental standards. Hence, it is generally based solely on the ecological pillar of sustainability.

Nonetheless, there is still a long way to go to accomplish and implement all these proposals, spread the initiative and build an academic community, and for various reasons. Firstly, there seems to be a conceptual and emotional distance between the media creation process (the so-called "behind-the-scenes") and the audiences. This could be as a result of "Hollywood starstruck factors", or in other words, the element of surprise that many films or television want to keep secret from their audiences, and which more often than not goes hand in hand with the behind-the-scenes process. Furthermore, the relationship between the content and the audience (as can be seen in phenomena such as the notion of alignment, parasocial relationships, and aesthetic distance) is greater than interest in the production. Consequently, this leads to a lack of social awareness by the general public and, hence, no demand or pressure is made on this particular sector. Furthermore, there is an absence of institutional support in terms of regulations and standards for monitoring the industry's carbon emissions [3] and recognition-in the form of awards or prizes for green or social minority representation (gender, race, LGBT+, etc.) - are insufficient, and this is significant given that many media industries in the European context depend on public finance. In other words, many European countries subsidize national programs for audio-visual arts, and in some cases, this includes intervention by the European Media program. In light of this, they could help and encourage productions to actually set and prioritize sustainable practices via subsidy lines that comply with sustainability principles. European productions may feel greater pressure for such intervention in comparison with the US model, since the subsidy model in Europe is not as wide-ranging. Nonetheless, in many countries, sustainability has not yet been established as a criteria for obtaining the necessary funding, or it is not recognized in any form.

It is important to note that "cancel culture" does not help to change bad or unsustainable practices, whether they be cultural, social, economic, or environmental, because instead of changing the structural programs, it attacks the individual. Cancel culture is a popular practice, widely discussed and implemented on social media, in which followers of public figures and companies withdraw their support, usually for breaking the norms of social acceptability or after they have done something objectionable or offensive, thus depriving them of attention "with the aim of making public discourse more diffused and less monopolized by those in positions of privilege. Conversely, cancel culture has also been framed as a form of intolerance against opposing views" [14]. This type of practice is led mostly by Generation Z, a demographic cohort following on from Millennials that is characterized as being the first generation considered to be fully digital natives.

Secondly, misinformation and misconception exist about the term "sustainability", given that as we have previously explained, it is all too often associated exclusively with environmental or ecological factors, in addition to the assumption that sustainable practices are prohibitively expensive, when sometimes reducing waste will in fact save production money [13]. "The discourse machinery of Hollywood manages to deflect popular criticism of the environmental ramifications of film production, and avoid governmental regulations" [12] (p. 27). Moreover, the alleged "star-system" blurs any attention placed on the behind-the-scenes that is not based on the celebrity figure, and the focus on media sustainability is usually tied to celeb causes. For example, Miley Cyrus' Happy Hippie Foundation, 
which helps homeless youth, mainly those of LGBT community in the United States, or Dicaprio's Foundation (LDF) which focuses on raising awareness about environmental issues.

Thirdly, and crucially, the plot's continuity or quality tends to be prioritized over highlighting sustainable practices. Famously, in the final season of Game of Thrones (HBO, 2011-2019), several plastic bottles and a polystyrene cup appeared on-screen, and instead of focusing on the nature of the material, critics and audiences, via Twitter, focused all the attention on the discontinuity within the plot rather than the environmental impact [15].

Nonetheless, one could argue that it is the job of academics, scholars, audio-visual marketing and PR departments to pivot the conversation towards environmental concerns. Certain companies, such as Earth Angel NYC, expressed this concern through social networks, though they did not create the necessary impact to change the course of the debate.

Fourthly, the heterogeneous, interchangeable, and time-consuming nature of audiovisual projects (advertisement, cinema, television, video clips, festivals, etc.) makes it hard to apply a standard, equally relevant sustainable plan. Moreover, [16] "platformization complicates the question of media concentration, as platform corporations integrate highly diverse businesses" (p. 650). Finally, the audio-visual sector relies heavily on its commercial success and does not have the obligation per se to act in a sustainable manner, except for those publicly-funded projects, which in some cases might have to answer to social and citizenship responsibility. Nonetheless, commercial success is still a priority for the industry and therefore, in a generic way, sustainability policies take a back seat when the product succeeds. In this sense, commercial factors come to prevail over the ideas of social responsibility and public broadcasting.

Nevertheless, this does not mean that the industry cannot tackle its environmental, political, and socio-economic impacts and use the medium's creativity to inspire and inform audiences. "Bigger, better, clearer pictures are the key to informed action" [17] (p. 248). This could be thanks to help provided by spokespersons (actors, musicians, influencers, etc.), also known as Ambassadors (as already being promoted by Earth Angel NYC), to media features, highlighting in their information brochures [12], and emphasizing their use in the credits, promoting green stamps and even prizes. These events are eco-friendly for creating reels. Such an approach would require media professionals and academics to take note of the work done by political actors, responding in creative, uncertain, and strategic ways to media sustainability crises.

\section{Materials and Methods}

\section{Towards a Definition of Media Sustainability: Green Shooting}

In the last few years, a new concept has emerged in the media field, known as Green Shooting. It is a countercultural, almost alternative concept that is linked to the financial, health, social, professional and educational concerns of the audio-visual field and its sustainable well-being. It is a concept used for information and conceptual purposes, since there is currently a lack of detailed theoretical studies. The concept usually seems to refer exclusively to an ecological or environmental definition. Nonetheless, as previously stated, it is often a misconception [13], as instead it has a broader meaning because it includes concepts such as equity, social justice, and the distribution of resources in the social imaginary. Many of the initiatives suggested and collected, in this article, have been developed, recommended and defined by activists and professional movements in the audio-visual sector through their own practices. Green Shooting's main objective is to systematize the information on good sustainability practices in the value chain of the audiovisual activity throughout all its phases: Pre-production production, post-production, distribution, exhibition, and consumption. Based on these practices, the audio-visual sector has been nourished by a series of proposals that give meaning to a concept that presents a slight controversy. Everything related to the thematization and introduction of Green Shooting elements in filmographic plots causes the freedom of authorship to sometimes clash with recommendations aimed at preserving the environment, owing to issues linked 
with the narrative or the actual production. The object of intervention of Green Shooting policies can be tangible or intangible, depending on the product:

(a) "Intangible" refers to those incorporeal aspects of media that can be modified to be sustainable from the content to a working team's interculturality. The intangible elements of any production contain aspects that thematize the sustainable condition of the productions and take care of them. This classification includes components that have to do with the well-being of work teams, tolerance of multiculturalism, gender equity, concern for animal and human respect, and the environment.

(b) "Tangible" refers to corporal aspects that can be modified to be sustainable, such as eco-vehicles, recycling bins, opting for vegan makeup and for environmental lighting, work materials on- and off-screen, technical equipment, accommodation, and avoiding paper script. etc.

The authors propose a theoretical route through the different stages of the development of a production, explaining the practices that follow a logical order of creation and completion while pointing out the object of intervention (see Figure 1). It should be noted that most of the proposals have already been implemented in the practical field.

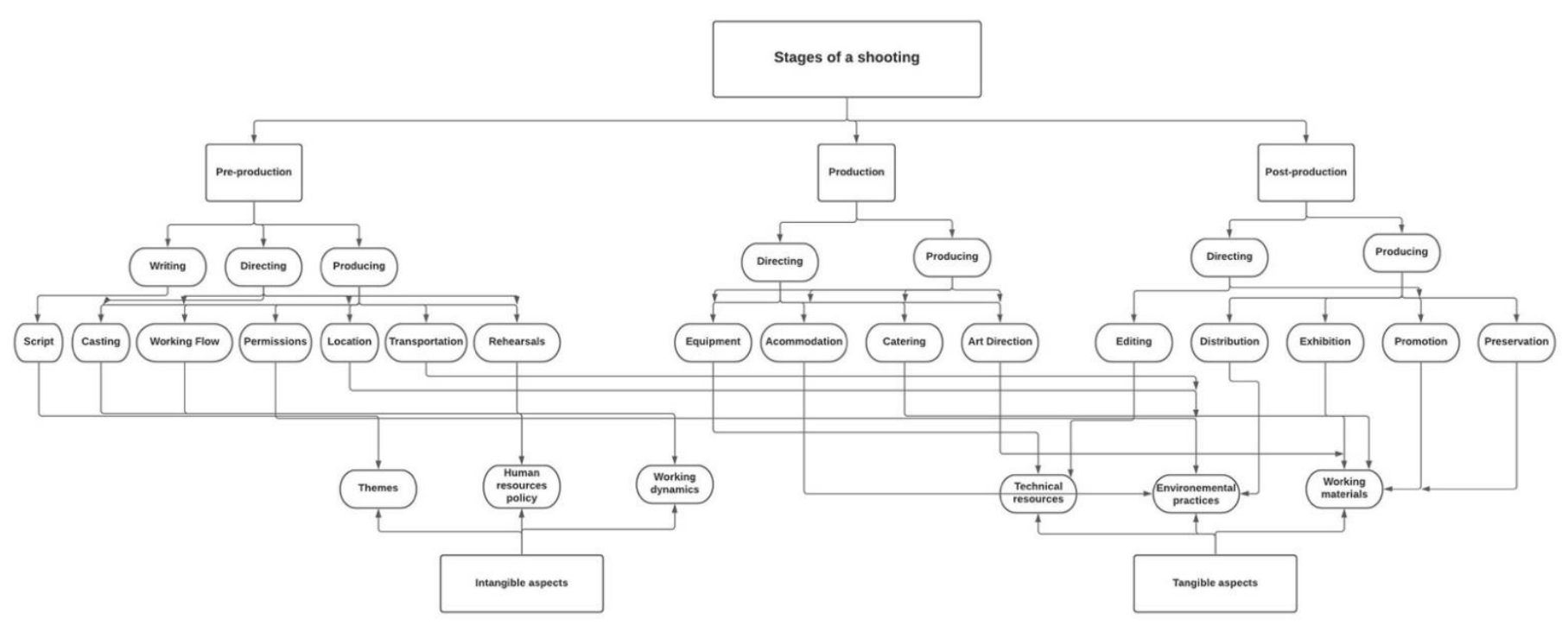

Figure 1. The stages of shooting: A framework for understanding the stages of audiovisual practices. Source: Own.

\section{Results}

\subsection{Field of Action: Pre-Production}

The term pre-production includes (see Figure 1), in any audio-visual creative development, all those actions prior to the moment filming begins, from ideation to locations, through aspects such as scriptwriting, production and production planning, design, artistic direction, technical decision-making or casting. Though it would not be strictly included in this section, all activities related to training for future audio-visual professionals should consider the elements of this section as crucial. Thus, probably, the most important action that should be implemented in the industry and educational systems is that of training to avoid future mistakes. Hence, the scientific and academic community needs to reflect this, even in their projects. As Green Shooting is a relatively new concept, in this training period, audio-visual projects could include in this first phase a role understood as an eco-consultant/assistant/supervisor [13], a newer role which, though the term it seems to refer solely to environmentalism, it also includes the other two axes of sustainability. Its responsibility is to coordinate all departments' activities so that all of them comply with sustainable practices. It is important to note that even with the incorporation of this new role, those in charge and who make the final decisions are the heads of each unit, under the 
instructions of the producer. The role of eco-consultant/assistant/supervisor is to check that all creative processes follow the protocols.

Moreover, the Catalan group 4R (2020), a compound of OPA (Observatory for AudioVisual Production), when they set up a line of joint work on sustainable cinema (together with Associate Producers of Catalunya (PAC), Catalunya Film Festivals (CFF) and Suncine International Environmental Film Festival and with the support of the Department of Culture of Catalonia, Barcelona City Hall and Barcelona Provincial Council), they found that a need existed to raise awareness among the crew and other external actors. For example, to negotiate sustainable practices with suppliers [18]. Once this first action has been established, it is important to use a carbon calculator to help track and report the carbon footprint of the project's production. Recently, Fremantle (an independent group of talents comprising activists and figures, studios and producers that operate in 31 countries across the world) and BAFTA's Albert (the authority on environmental sustainability for film and TV industries in the UK) produced an updated version that was devised to be used as a benchmark. The figure of the eco-consultant then becomes a priority, in addition to other figures in the creative processes, for example, legal advisers on copyright, filming permits and the contractual regime of workers.

From a tangible standpoint, many things have been proposed by Green Shooting policies concerning the script process, especially regarding the digitalization of many of the phases of the process. If possible, productions should opt for digital documents and collaborative programs in the cloud, to avoid paper-based scripts, and opt for video meetings, instead of attending meetings in person if they require single-use transport. Nonetheless, when the use of paper is unavoidable, it should be recycled, printed doublesided in black-and-white and using ecological inks and sources (eco fonts), as well as the eco-setting on energy-efficient (IT and appliances) or electronic disposal equipment. Due to the COVID-19 outbreak, many television series productions, such as Grey's Anatomy (ABC, 2005-), have already implemented an all-paperless script formula, in a sense advancing their sustainable practices for both health and environmental reasons [19]. The topics chosen and what that derives from the creation and construction of the plot can also implement sustainable practices. It is not a question of conceiving audio-visual products out of a political correctness that can rarely be adapted to the reality of the narration, but instead to become aware of how the approach to specific topics and everything they comprise can help to deal in greater depth and responsibility with certain aspects.

The audio-visual sector has to "commit to foster an entertainment industry that is not only sustainable, restorative and circular but also inclusive, equitable and intersectional" [13]. Hence, in order for it to recover, the industry needs to map out a systemic justice plan. Thus, in an intangible way, Green Shooting policies suggest that, since film and philosophy [20] are "a way of evoking ethical experience and thereby inviting further ethical-critical reflection" (p. 53), whenever possible in terms of the plot and the consistency of the narrative, scripts can include characters that align with ecological practices and social justice in the fabric of their methodology and frameworks. Though again, never to the detriment of the quality and original creative purpose of the authors [21]. For instance, the Amazing Spiderman-2 included a scene in which a kid was shown carrying an environment-friendly school project (Webb, 2014), or 3 generations (Dellal, 2015) in which the movie explores a radical proposition for a transgender movie in tastemaker culture, plus many people from the LGBT community successfully fought the MPAA's R rating. Hence, tackling social justice issues. This example serves to illustrate that only when possible, art direction can add sustainable initiatives when it does not change the plot but that eventually, over time, can switch the collective imagination. On the other hand, again when possible for plot reasons, production could guarantee a minimum intersectional and intercultural representation at the moment of casting minority groups on-screen. Even more important and feasible than the artistic crew, the recruitment of the technical crew should consider the same protocols when hiring the work team off-screen by hiring them in different roles and categories. Since Green Shooting also pays attention to social and cultural 
aspects, hiring goes hand in hand with the policy for the crew. For this reason, working schedules should try to guarantee fundamental rights, specifically for vulnerable groups such as children (not exceed the legal amount of time), respecting maternity leave, and paternal and maternal timings. This is one aspect that has now been more controlled and regulated, especially by the respective unions in this area. The Green Shooting movement also seeks to integrate social justice and equity policies applied in this regard and make them compatible with others that coexist in a complex and holistic process such as an audio-visual shoot.

Thus, these actions also affect (positively) the working flow and professional dynamics, and by opting for socially responsible organization, audio-visual productions are already committed to achieving social, cultural and environmental goals. As Brereton [2] explained, Hollywood can help to bring to the forefront education and ethical agendas regarding core ecological values and ideas. Nonetheless, this can come at a cost to aesthetic freedom. In other words, it gelds the freedom of expression and the artistry of the authors. In other words, in this new social, environmental and economic ecosystem, the media industry could try to balance ethical and social corporate responsibilities, particularly when publicly funded, without having to oblige to concepts such as greenwashing, edutainment and politainment. Greenwashing refers to a form of marketing implemented in a deceptive way to promote the perception that an organization's products, objectives, or policies respect the environment for the purpose of increasing their profits. However, more often than not, evidence shows that they spent significantly more money advertising their "greenness" than on actually implementing green practices, thus resulting in a green facelift. "Hollywood's green conscience to this point is a marketplace conscience, torn in conflicting directions by the forces of sustainable practices, Hollywood studios have begun to tighten the efficiency and renewability of their raw material" [12] (p. 27). Both edutainment and politainment are terms produced by the conjunction of two others, and they tend to either educate or involve audiences in political communication and affairs through media. The former unifies education and entertainment while the latter unifies politics and entertainment. The latter two could be described as film or audio-visual fields [22] "undergoing an "ethical turn" - along with other areas of the humanities-in reflecting upon cinema as a distinctive way of thinking through ethical concerns" (p. 1).

Concerning the locations of the shooting, many aspects need to be taken into consideration, from tangible to intangible objects of intervention, from transportation to cultural tourism. Most of them are related to the material and non-material respect for the environment. The latter is defined as the accuracy representing cultures and places. This is strictly linked to cultural tourism, as mentioned previously, and is understood as a sort of special interest tourism involving leisure travel to view or experience the distinctive character of a place, its peoples and its products or cultural productions [23]. As stated above, film and television, mostly, play a huge role in attracting tourism to a specific place, but not without a cost. This can range from the possible effects on the environment and landscape (soil and subsoil, hydrology, flora, fauna, etc.) to its impact on local communities when selling specific imagery. The effects of "touristification" and gentrification from audio-visual shootings and visiting sacred places is one aspect to consider when planning a responsible and sustainable audio-visual oeuvre. Despite this concept's abstraction, the exploitation of environments and the material and immaterial aspects of spaces, like the culture associated with it, is a crucial element to consider when planning a shooting with these characteristics.

Thus, it seems essential to opt for territorial planning. Territorial planning can be defined "as the complex process of integration of various instruments and actions, of a diverse nature, both spatial and non-spatial, in order to shape, on a large scale, the territory and the activities that they develop" [24]. Sustainable design practices should be used whenever possible, such as natural lighting, air conditioning, solar energy, etc. and showing a methodological, disciplinary and political coherence to the actions. To that end, Cubeles [25] and Tenerife Film Commission (2020), a department of the SPET- Tenerife 
Tourism Corporation, created in the year 2000 to promote audio-visual productions on the island by producers from Tenerife and abroad, proposed the following 17 elements: (1) Encouraging the diversity of the territory by promoting and preserving cultural facilities and local values, and maintaining the reference of its biophysical matrix, (2) finding out about the environmental characteristics (territorial sizing) and rules of locations and facilities to preserve the landscape as a social value and an economic asset of the territory, (3) moderating soil consumption, (4) encouraging the social cohesion of the territory and avoiding the spatial segregation of the urban areas by (5) protecting and enhancing the urban heritage that forms the backbone of the territory, (6) ensuring the compact and continuous nature of growth by encouraging productions to choose the lowest number of locations and aiming for them to be within a short distance. Thus, making mobility a right and not an obligation, (7) strengthening the nodal structure of the territory through urban growth, (8) facilitating public transportation through the polarization and compactness of settlement systems, (9) locating equipment, in order to determine the optimal location, (10) improving the quality of life in general, paying particular attention to social exclusion and neighborhood renewal, (11) publicly demonstrating a commitment to sustainable development through the management of assets and equipment, and (12) rehabilitating depressed rural or urban areas and prioritizing areas with cultural deficits.

Ecoprod [26], a brand signature made up of six industry players (ADEME, AUDIENS, Île de France film Commission, DIRECCTE IDF, France Télévisions and TF1) launched this brand initiative in 2009 to mobilize audio-visual professionals, develop and provide professional resources to reduce the environmental footprint of the sector. In their guidelines, there is specific regard for transportation, which not only encourages producers to create a travel plan ahead of filming but also 16 additional measures, as follows:

1. Identify public transport opportunities, provide information to the crew about the nearest and eco-friendly options (such as bike share stops to the filming location). Optimize trips and track driven kilometers and opt for videoconferences.

2. Choose carpool and electric vehicles (also solar-driven vehicles, Hybrid, CNG, LPG or electric) for non-local crew members and apply eco-driving principles.

3. Choose accommodation as close to the filming location as possible.

4. Organize carpooling between crew members.

5. Debate with car hire companies about their lorry and vehicle fleet's energy efficiency and rent low-emissions or hybrid/electric vehicles.

6. Opt for large-capacity vehicles (minibus, people carriers, etc.), trucks need to be CNG, LNG, or Diesel EURO 6, and ensure vehicles are properly maintained.

7. Optimize equipment loading and delivery.

8. Organize security during the night for equipment trucks to remain parked at the filming location and avoid needless back-and-forth travel.

9. Select transport companies engaged in sustainable development (bicycles, skating, public transport for short distances)

10. Take trains rather than flights for trips under more than $5 \mathrm{~h}$. If necessary, purchase carbon offsets for long distances.

Within the pre-production process, many other aspects derived from the activities previously discussed can be found. This article aims to reflect only the most outstanding examples and those that, more directly, have continuity in the different phases of development of audio-visual productions.

\subsection{Field of Action: Production}

The production phase (see Figure 1), strictly refers to the shooting period of any audiovisual product. As a matter of economy and sustainability, shooting tends to focus on filming days, and in this regard, sustainability policies advise trying to group the scenes as closely as possible to produce savings in many ways. This logic of grouping filming practices, which has an atavistic function, is usually suggested as a general approach: Streamlining time and resources and prioritizing needs. Discontinuous recording of movie sequences 
meets this need. For the effective development of Green Shooting, discontinuous thinking is also required, which allows us to work according to the dynamics of use and savings.

In that sense, communication is a crucial factor in this phase; producers should collaborate with local environmental and solidarity organizations in all the active markets, whenever possible, concerning the use of equipment, policy for non-human beings, and materials. Concerning animal policies, as many enterprises from other sectors are already doing, producers should be encouraged to use, when possible, vegan-friendly products and avoid scenes including animals. For instance: Make-up or clothing vegan products. While these types of initiatives are well received by teams, in theory, the synergy of timeconsuming productions and their experience with these new sustainable products can lead them to go back to many old practices. For this reason, many specialists are creating charters with the main initiatives and distributing them to the crew (digitally) and leaving them on display in strategic locations [13]. One of the most consuming production elements is lighting, not only for its artistic value but because it is needed artificially in many cases. Hence it produces an environmental impact, to avoid it as much as possible Ecoprod [26], and $4 R$, which is a joint Catalan proposal for sustainable audio-visual has suggested several measures, which can be gathered in the following:

1. There should be a preference for the use of LED bulbs and other energy-saving technologies.

2. Where a connection to the public grid is possible, try to use it, and only when there are no public grid generators should only be allowed for a maximum of 3 days per location, when possible use stage 5 generators or efficient hybrid generators with an integrated battery system. If generators are under $10 \mathrm{~K}$, they should only be allowed with solar/wind, propane/butane or gasoline.

3. Rent high-efficiency digital equipment from local providers whenever possible.

4. Raise awareness among the crew on how to save energy (encourage the use of electricity, when available, from renewable sources and batteries dispensers).

5. Limit waste and overconsumption of consumables (gaffer tape, grips, straps, ropes, etc.).

Everything related to sound engineering could be expressed, with less impact, to similar recommendations as those reflected in the lighting section.

Regarding accommodation and catering, as many other departments, it is mostly based on local action and proximity products, ranging from choosing a supplier committed to sustainable development, green-certified hotels, investing in local sourcing, serve local, seasonal food that is organic and/or fair trade, packaging reduction with reusable bags and containers that can be customized, e.g., using water bottles, to evaluating the purchase of consumables to avoid unnecessary waste. As they did in Amazing Spiderman-2 (Webb, 2014) whenever there are leftovers, many enterprises and studios now consider donating the surpluses to local associations. Nonetheless, this is not always possible worldwide due to possible health-related issues. Moreover, catering is strictly linked to waste management, as many policies related to Green Shooting (such as those presented by $4 \mathrm{R}$ ) propose creating an established plan where reusable material, hazardous and non-recyclable waste and products are disposed of and setting up sorting bins and displaying waste recycling signs. Another important area of waste management involves the construction of sets, from planning to sorting. It is highly recommended that producers consider renting from other crews or suppliers and reusing materials for other production projects instead of buying or building from scratch, but if necessary, the creators are strongly encouraged to opt for local, recycled, certified, sustainable and plant-based materials such as harvested wood and to avoid toxic products such as Styrofoam, PVC, and Isocyanates for reasons of sorting. These types of actions not only can reduce waste, but also save money in this particular phase. These savings can be used for this or other phases [13]. As Ecoprod states [26], if there is any material left, not just specific containers should be provided (for paint and water disposal to "general" recycling forms), efforts should be made to ensure that protocol is followed as strictly as possible, and that materials are duly collected and recycled. For instance, if temporary buildings or architectural structures are constructed for film or TV production, 
they can either be used in other productions or all their elements sold in order to carry out a complete recycling. Nonetheless, many times equipment or structures become obsolete, and if this happens, many common Green Shooting proposals advocate for appropriate disposal organization and specific recycling of waste electrical and electronic equipment.

Concerning art direction, which includes the construction of sets, props, hair, and makeup, there are a range of alternatives suggested by many production companies such as Broadway Green Alliance [27]. The most common initiatives in the costume department are the following: Avoid one-use wardrobe, use eco or certified detergents, energy-efficient washing machine, certified detergent, low temperatures, reuse, borrow, rent and buy second-hand clothing or sustainable options (fabric components, origin, and sourcing) such as recycled cotton. Once the project is done, specific actions are recommended, from selling them to the crew, second-hand stores or costume rental companies, donating them to charity organizations, and reusing or recycling accessories to keep clothing and accessories for another project, as many previous film projects have done, especially if it is within the same studio. For instance, a skirt is used in Manolete (Meyjes, 2008) and afterwards in Brooklyn (Crowley, 2015) or a dress is chosen for The Duchess (Dibb, 2018) and then altered for The Scandalous Lady W (Folkson, 2015). In the makeup and hair department the most recurrent eco-friendly options are based on the materials (vegan or certified options) and avoiding single-use products such as make-up wipes or aerosols. Nonetheless, due to the COVID-19, many of these alternatives have been altered: Wardrobe is now selected using a hazmat suit for each piece to avoid any hands-on contact, while at the same time, to protect the health of the team, masks and face shields are used, and flexiglass is put between each station for hair and make-up [19], which tends to be single-use or made out of plastic, so it is a question of finding a balance between the social and the ecological impact. Meanwhile, the shooting material itself is ultimately one of the elements for consideration, according to Green Shooting policies. As in the case of scripts, everything that goes through non-polluting digitization processes meets sustainable filming purposes.

New filming and storage techniques for the footage facilitate this task, but in some cases, they also require the existence of digital servers that can interfere, in varying degrees, with the will to introduce pro-Green Shooting practices. As Carruth pointed out [28], the micropolitics of energy are defined as individual practices fueled by our rapidly-growing social media culture of connectivity that relies on servers. As Breenan [29] discusses in her chapter "Making Data sustainable", digital servers and their backups, known as recovery data servers, can cause social, environmental, political, logistical and structuring concerns. Many of these replicas are due to our obsession with self-archiving, superabundance, superfluous, redundancy, and instantaneity [30]. As Brennan points out [29] the physical placement of data centers can intensify and downplay geopolitical risk since it is harder to pin them down, thus enhancing geographical spread by deliberately locating them in lax regulatory and state borders, and replicas can even be located in a different geographic location (pp. 64-65). Moreover, the infrastructures still derive from the burning of fossil fuels, though some are powered significantly by renewable energy. Hence it is no surprise that data servers are inefficient and power-hungry due to humans' unsustainable digital demands. Thus, a redundancy movement takes place [29], which tries to find "affinity with non-digital efforts to redundancy and thereby cut emissions and [ ... ] generate demand for eco-friendly backup technologies" (p. 69).

\subsection{Field of Action: Post-Production}

The authors consider "post-production" (see Figure 1), in the etymological sense of the term, since there is no scientific consensus. Therefore, authors call "post-production" everything that is done "after and beyond the production", and this includes "editing, and visual and sound treatment", but also "exhibition and distribution". This approach is taken since the vertical integration of the sector (especially in the line of productiondistribution-exhibition) problematizes differentiation between these sectors. Although, as its title indicates, the post-production process is carried out at the end of a project, 
it should be previously conceived not only to promote more sustainable practices but also to produce financial profit (such as the substitution of scenarios, in some instances). For this reason, a model of the environmental impact of the broadcast chain needs to be developed from the beginning. Since post-production is linked with ICTs, there needs to be an analysis of technology sourcing, existing and future broadcast technologies to be created, implemented and evaluated through common standards. Hence, as Ecoprod suggests [26], post-production studios should try to implement an environmental, energysaving approach (production room, equipment, practices, equipment disposal, green energy), and efficient and certified equipment.

With regard to editing, special effects, distribution, and exhibition, it follows previous options seen in other fields of action; it mostly opts for a digital tendency. Virtual broadcasting techniques can limit energy consumption, avoid harmful products and opt for digital special effects (drone) to circumvent environmental dangers that need to be taken into consideration, specifically those related to the ecology of human health. It is important to note that according to Evans [3], "video viewing will account for 82 per cent of all Internet traffic, with overall Internet traffic accounting for more than 1 percent of global emissions". This massive impact will need a greener transformation of the ICT sector, which might spur scrutiny through consumer engagement with sustainability. Nonetheless, other authors [29] argue that since data preservation strategy is based on "totality, regularity, continuity, locality, longevity, security and integrity" (p. 56) many of the practices have shifted from localized data storage to cloud services, and while it seems sustainable, this is untrue, since it increases energy consumption and carbon emissions. The reasoning behind this erroneous idea is based on the image of the cloud as a metaphor, because it pushes [29] "away from the materiality of information. Thus, cloud backup is paradoxically contributing in many ways to climate change at the same time as it is striving for the opposite" (p. 56). In contrast, several reports state that "gaming consoles may become more energy-efficient as game time increases since overall power usage of devices will only increase by 4 per cent" [3]. However, authors such as Milburn [31] believe that games have escalated the associated environmental and geopolitical pressures because "the engineering of game hardware relies on scarce resources, including rare earth. At the same time, the growing ubiquity of powerful console systems and high-performance PCs places more and more demands on the worldwide energy infrastructure" (p. 78). Moreover, video games also play a double role. For instance, through its content, Final Fantasy VII made its gamers aware that by playing they were contributing to the environmental crisis. So, in a sense, the game was changing its fantasy into proactivity, enabling critical thought. Nonetheless, others [31] were "overtly skeptical about the green politics of the game" (p. 81). These antithetical arguments show a need for intersecting research on sustainable cultures of media use and back-up systems as well as a need to rethink the definition of what constitutes media studies, and in particular, green media technologies, which could bring theoretical innovation. However, analogue distribution and exhibition still require deep reflection on the mechanics that can best foster a sustainability culture in the audio-visual industry, from the transport of copies to the equipment intended for projection, especially in large rooms. Precisely linked to the exhibition is the entire sector that accompanies it, especially the food industry, which is also urged, from the platforms for implementing Green Shooting policies, not to give up the health practices highlighted earlier on the subject of catering.

Sustainable actions do not finish as soon as the post-production does; they carry on through the supply chain until the promotion, communication, and preservation of the product or brand itself. While merchandising has been one of the things used to catch audiences' attention even prior to the realization of the product (e.g., crowdfunding sites), Green Shooting policies recommend avoiding plastic material giveaways and opt for permanent products. Along similar lines, a policy should be developed on sustainable sourcing for production and broadcast resources. Doing so would help to preserve it, ensure long-lasting use, give the product or brand itself a longer life and raise audience awareness, which is still one of the main issues of the sector. Furthermore, a final post-filming carbon 
footprint calculation needs to be done to evaluate how much impact the production caused. This would involve checking whether the first evaluation was done precisely and if there is room for improvement. The same way an ecological evaluation is made, it is important to check the quality of the service (especially when hiring new eco roles) and their degree of satisfaction and participation and to see which social aspects can improve. Along the same lines, financial results and their impact (direct and indirect) should be assessed in order to analyze the growth of the local and international circular economy.

Concerning preservation, both the processes involved and the dynamics of related activities involve considerable energy expenditure, which is associated with pollution. Green shooting policies require a reflection on the responsible healing of audio-visual creations, their maintenance, and their life beyond the immediate moment of exhibition. This involves a strategic redefinition of the uses and dynamics of housing and circulation of productions. Research on more green-friendly preservation processes and training in this specific area are seen as necessary elements to facilitate a substantial improvement in the development of a sustainability policy for the audio-visual. Finally, it is essential to showcase-through events, exhibitions, workshops, or presentations (online and physically) - the best practices used to inform and educate the audience and the rest of the industry of the Green Shooting and its practices.

\section{Discussion}

This concept paper presents an overview of the term of Green Shooting, and it also brings together all the audio-visual practices that several companies and initiatives worldwide have already implemented as emerging solutions to mitigate their negative impact. Moreover, it shows that applying those initiatives can be quite cost-effective or profitable as many practitioners such as CEO of Earth Angel NYC, Emillie O'Brien and New York City producer, Lydia Dean Pilcher have pointed out [32].

Experiences worldwide suggest that sustainable initiatives are more successful when there is buy-in from industry practitioners [33]. However, there is a lack of academic involvement, if the audio-visual sector and academia amalgamation could lead to more cohesive industry development in sustainability standards. For this reason, the authors propose a set of standard guidelines to be explored and used in academic settings and explore the state of the art of what is a fairly embryonic subject. The basis of Green Shooting is to create knowledge on media practices on sustainability and a culture of "green literacy" in the field of audio-visual, since a newer educated media generation could avoid the correction of specific practices. On the other hand, it could add more interdisciplinary training in roles such as the eco-assistant or supervisor, an important role for the future of the audio-visual industry. In other words, media professionals and academia need to re-educate-including political-economic critique — the system that is already established. As Henderson [34] points out, the necessity for "the implementation of educational proposals seeks political opening through scholarship and expressive experimentation as a route to collaboration and solidarity." Moreover, by analyzing all the pre-existing options, it is clear that, in order to maintain cultural systems, recognition from the industry is needed. An interdisciplinary vision is also needed between various sectors, a cross-cultural approach between disciplines from a more social and human perspective to scientific and technological approaches if the audio-visual sector wants to ensure that their SDGs are being accomplished. One of the aspects to consider, linked to the need to create literacy in the field of Green shooting, is to invest in research on what elements can contribute to the implementation of Green Shooting policies and the dissemination and dissemination of this issue among the general public.

Author Contributions: Conceptualization, M.L.-M. and M.J.-M.; methodology, M.L.-M. and M.J.-M. writing-original draft preparation and review, M.L.-M. and M.J.-M. All authors have read and agreed to the published version of the manuscript. 
Funding: This research was funded by Pompeu Fabra University, under grant UPF Planetary WellBeing.

Institutional Review Board Statement: Not applicable.

Informed Consent Statement: Not applicable.

Data Availability Statement: The data presented in this study are available in the main manuscript.

Conflicts of Interest: The authors declare no conflict of interest. The funders had no role in the design of the study; in the collection, analyses, or interpretation of data; in the writing of the manuscript, or in the decision to publish the results.

\section{References}

1. Balló, J.; El Rodaje Sostenible. La Vanguardia. Available online: https://www.lavanguardia.com/cultura/20181114/45291759931 8/el-rodaje-sostenible.html (accessed on 14 November 2018).

2. Brereton, P. Eco-cinema, sustainability and Africa: A reading of Out of Africa (1985), The Constant Gardener (2005) and District 9 (2010). J. Afr. Cine. 2013, 5, 219-235. [CrossRef]

3. Evans, C.; Julian, I.; Simon, F. The Sustainable Future of Video Entertainment from Creation to Consumption; Futuresource Consulting Ltd.: Hertfordshire, UK, 2020; pp. 1-34.

4. Starosielski, N. Pipeline Ecologies. In Sustainable Media: Critical Approaches to Media and Environment, 1st ed.; Starosielski, N., Walker, J., Eds.; Taylor \& Francis Group: New York, NY, USA, 2016; pp. 38-55.

5. UCLA Institute of the Environment \& California Integrated Waste Management Board. Sustainability in the Motion Picture Industry. 2006. Available online: https:/ / www.ioes.ucla.edu/wp-content/uploads/mpisreport.pdf (accessed on 1 January 2021).

6. Parks, L. Field Mapping: What Is the "Media" of Media Studies? Telev. New Media 2020, 21, 642-649. [CrossRef]

7. Amin, S.; Making Fun of How South Asians Talk: A History. Atlantic, 2 February 2018. Available online: https: / www.theatlantic. com/entertainment/archive/2018/02/trump-modi-india-south-asia-accent-apu/551696/ (accessed on 7 March 2021).

8. Lopera-Mármol, M.; Green Shooting y Rodajes Sostenibles: La nueva tendencia del sector audiovisual que ha llegado para quedarse. Observatorio de Cibermedios (OCM). Available online: https:/ / observatoriocibermedios.upf.edu/green-shooting (accessed on 20 February 2019).

9. Fitzpatrick, R.K.; Behind Every Film Production Is a Mess of Environmental Wreckage. Vice. Available online: https: //www.vice.com/en_us/article/3kxjvk/behind-every-film-production-is-a-mess-of-environmental-wreckage?fbclid=IwAR0 -w24u0V4wPEUP26o81ZKYau7zZ0vcrXhT_iwx16xHZtQqKEt4R6QBW4Q (accessed on 15 October 2019).

10. Bruner, R.; Tourists Caused Too Much Damage to the Beach from Leonardo DiCaprio's the Beach. TIME. Available online: https:/ / time.com/5297042/leo-dicaprio-beach-closure/ (accessed on 31 May 2018).

11. McKinney, T. Ecotourism. Int. Encycl. Primatol. 2016. [CrossRef]

12. Vaughan, H. 500,000 kilowatts of stardust. In Sustainable Media: Critical Approaches to Media and Environment, 1st ed.; Starosielski, N., Walker, J., Eds.; Taylor \& Francis Group: New York, NY, USA, 2016; pp. 23-37.

13. O'Brien. Earth Angel NYC. 2020. Available online: https:// www.earthangel.nyc/ (accessed on 27 January 2020).

14. Velasco, J.C.; De La Salle University. You are Cancelled: Virtual Collective Consciousness and the Emergence of Cancel Culture as Ideological Purging. Rupkatha J. Interdiscip. Stud. Humanit. 2020, 12, 1-7. [CrossRef]

15. Lopera-Marmol, M.; El Green Shooting en el món Audiovisual. Observatori de la Producció Audiovisual (OPA). Available online: http:/ / www.pac.cat/cronica-green-shooting-ficma/ (accessed on 23 March 2019).

16. Poell, T. Three Challenges for Media Studies in the Age of Platforms. Telev. New Media 2020, 21, 650-657. [CrossRef]

17. Robles-Anderson, E.; Liboiron, M. Coupling Complexity: Ecological Cybernetics as a Resource for Nonrepresentational Moves to Action. In Sustainable Media: Critical Approaches to Media and Environment, 1st ed.; Starosielski, N., Walker, J., Eds.; Taylor \& Francis Group: New York, NY, USA, 2016; pp. 248-263.

18. OPA. Audiovisual Sostenible. 2020. Available online: https:/ / www.upf.edu/web / opa (accessed on 27 January 2020).

19. Donald, L.P.; Baker, F.W.; 'Grey's Anatomy' Cast and Crew Return to Set with New Safety Precautions. Good Morning America: ABC. 2020. Available online: https:/ / www.youtube.com/watch?v=kytgfNKVU48 (accessed on 7 March 2021).

20. Sinnerbrink, R. Cinematic Ethics: Exploring Ethical Experience through Film, 1st ed.; Taylor \& Francis: New York, NY, USA, 2016; pp. 1-210.

21. Rust, S.; Monani, S.; Cubitt, S. Ecocinema Theory and Practice, 1st ed.; Taylor \& Francis: New York, NY, USA; Abingdon, UK, 2013; pp. 1-344.

22. Choi, J.; Frey, M. Cine-Ethics: Ethical Dimensions of Film Theory, Practice, and Spectatorship, 1st ed.; Taylor \& Francis: New York, NY, USA, 2014.

23. Adams, M.K. Cultural Tourism. In International Encyclopedia of the Social Sciences; Darity, W.A., Ed.; Macmillan: Detroit, MI, USA, 2008.

24. Folch, R.; Planificació Metropolitana Concurrent. Pla Estratègic Metropolità de Barcelona. 2005. Available online: https: //pemb.cat/ca/publicacions/planificacio_metropolitana_concurrent/70/(accessed on 1 January 2021).

25. Cubeles, X. Cultura i Sostenibilitat; Direcció General de Cooperació Cultural, Departament de Cultura, Generalitat de Catalunya, BCF Consultors: Barcelona, Spain, 2006. 
26. Ecoprod. Environnement \& Audiovisuel: La Nouvelle étude d'Ecoprod. Available online: https://www.ecoprod.com/ (accessed on 27 January 2020).

27. Broadway Green Alliance. \#GreenQuarantine: How to Succeed in Creating a Sustainable TV and Film Shoot. 2020. Available online: https: / / www.youtube.com/watch?v=3w1cgFY7wTg\&t=1610s (accessed on 7 March 2021).

28. Carruth, A. The Digital Cloud and the Micropolitics of Energy. Public Cult. 2014, 26, 339-364. [CrossRef]

29. Brennan, S. Making Data Sustainable: Backup Culture and Risk Perception. In Sustainable Media: Critical Approaches to Media and Environment, 1st ed.; Starosielski, N., Walker, J., Eds.; Taylor \& Francis Group: New York, NY, USA, 2016; pp. 56-77.

30. Zielinski, S. The Media Have Become Superfluous. Continent 2013, 3, 2-6.

31. Milburn, C. There Ain't No Gettin' Offa This Train: Final Fantasy VII and the Pwning of Environmental Crisis. In Sustainable Media: Critical Approaches to Media and Environment, 1st ed.; Starosielski, N., Walker, J., Eds.; Taylor \& Francis Group: New York, NY, USA, 2016; pp. 77-92.

32. Heidsiek, B.; Green Film Shooting: Sustainability Reloaded. Cineuropa. Available online: https://cineuropa.org/es/newsdetail/ 323910/ (accessed on 8 March 2017).

33. Victory, J. Green Shoots: Environmental Sustainability and Contemporary Film Production. Stud. Arts Humanit. 2015, 1, 54-68. [CrossRef]

34. Henderson, L. Making Things Together: Expressive Culture as Research Practice; Public Lecture; University of Pennsylvania: Philadelphia, PA, USA, 2017. 